\title{
Comparison of Bayesian quantile and frequency-oriented regressions in studying the trend of discharge changes in several hydrometric stations of Gorganroud basin in Iran.
}

\author{
Khalil Ghorbani $^{1}$, Meysam Salarijazi ${ }^{1}$, Sedigheh Bararkhanpour ${ }^{1}$, and Laleh Rezaei \\ Ghaleh $^{2}$ \\ ${ }^{1}$ Gorgan University of Agricultural Sciences and Natural Resources \\ ${ }^{2}$ Urmia University
}

December 14, 2021

\begin{abstract}
Climate change causes fluctuations in temperature and precipitation. As a result, it affects the discharge of rivers, the most important consequence of which is the tendency toward extreme events such as torrential rains and widespread droughts. River discharge is one of the most important climatic and hydrological parameters. Investigating the changes in this parameter is one of the main prerequisites in the management and proper use of water resources and rivers. Most trend detection studies are based on analyzing changes in the mean or middle of the data. They do not provide information on how changes occur in different data ranges. Therefore, to investigate parameter changes in a different range of the data series, various regression models were proposed. Frequentist quantile regression and Bayesian quantile regression models were used to estimate their trend and trend slope in different quantiles of discharge in different seasons of the year for Arazkouseh, Tamar, and Galikesh stations of Gorganroud basin in northern Iran with the statistical period of 1346-1396 (1966-2016). The results show that in most seasons of the year, high discharge rates for all 3 stations have decreased with a steep slope, and only in summer, Tamar and Galikesh stations have had an increasing trend, but low discharge rates have not changed significantly. Spatially, the discharge values at Arazkouseh station have a decreasing trend with a higher slope rate, and in terms of time, the most decreasing trend has been in spring. Comparing the models also shows that the Bayesian quantile regression model provides more accurate and reliable results than the frequency-oriented quantile regression model. In general, quantile regression models are useful for predicting and estimating extreme high and low discharge changes for better management to reduce flood and drought damage.
\end{abstract}

\section{Hosted file}

@HP-Format . docx available at https : //authorea.com/users/451083/articles/549335-comparison-ofbayesian-quantile-and-frequency-oriented-regressions-in-studying-the-trend-of-dischargechanges-in-several-hydrometric-stations-of-gorganroud-basin-in-iran 

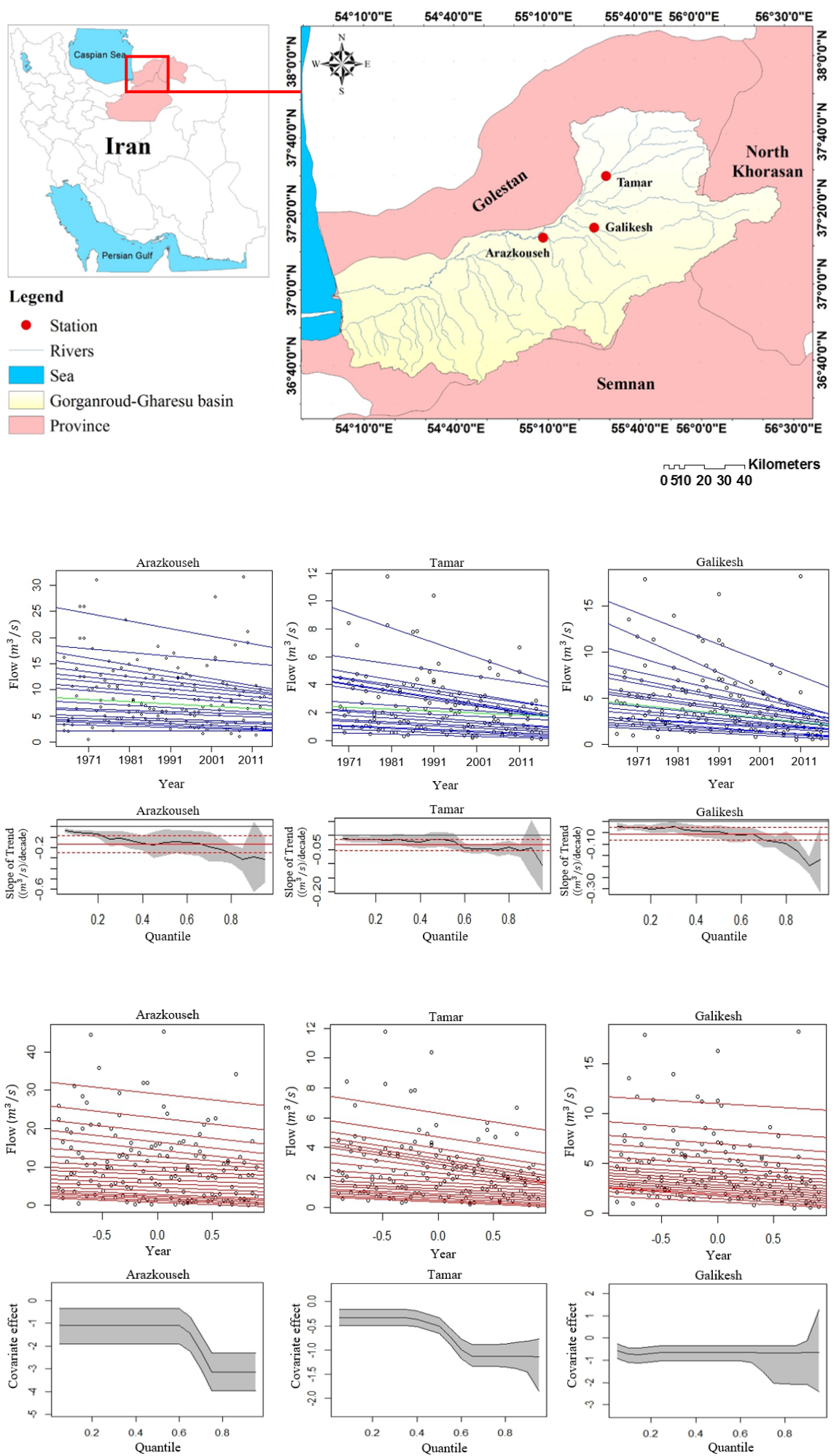

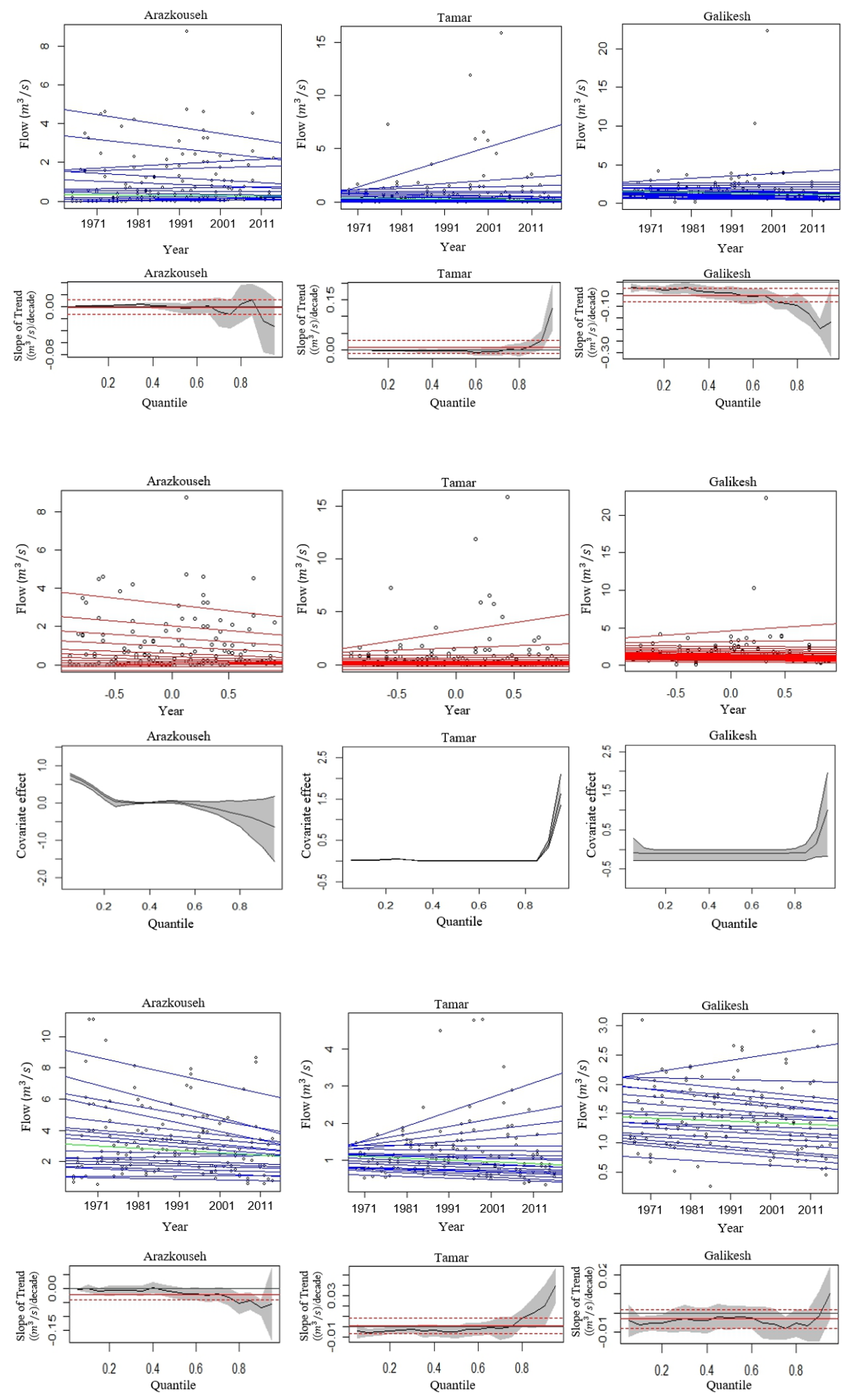

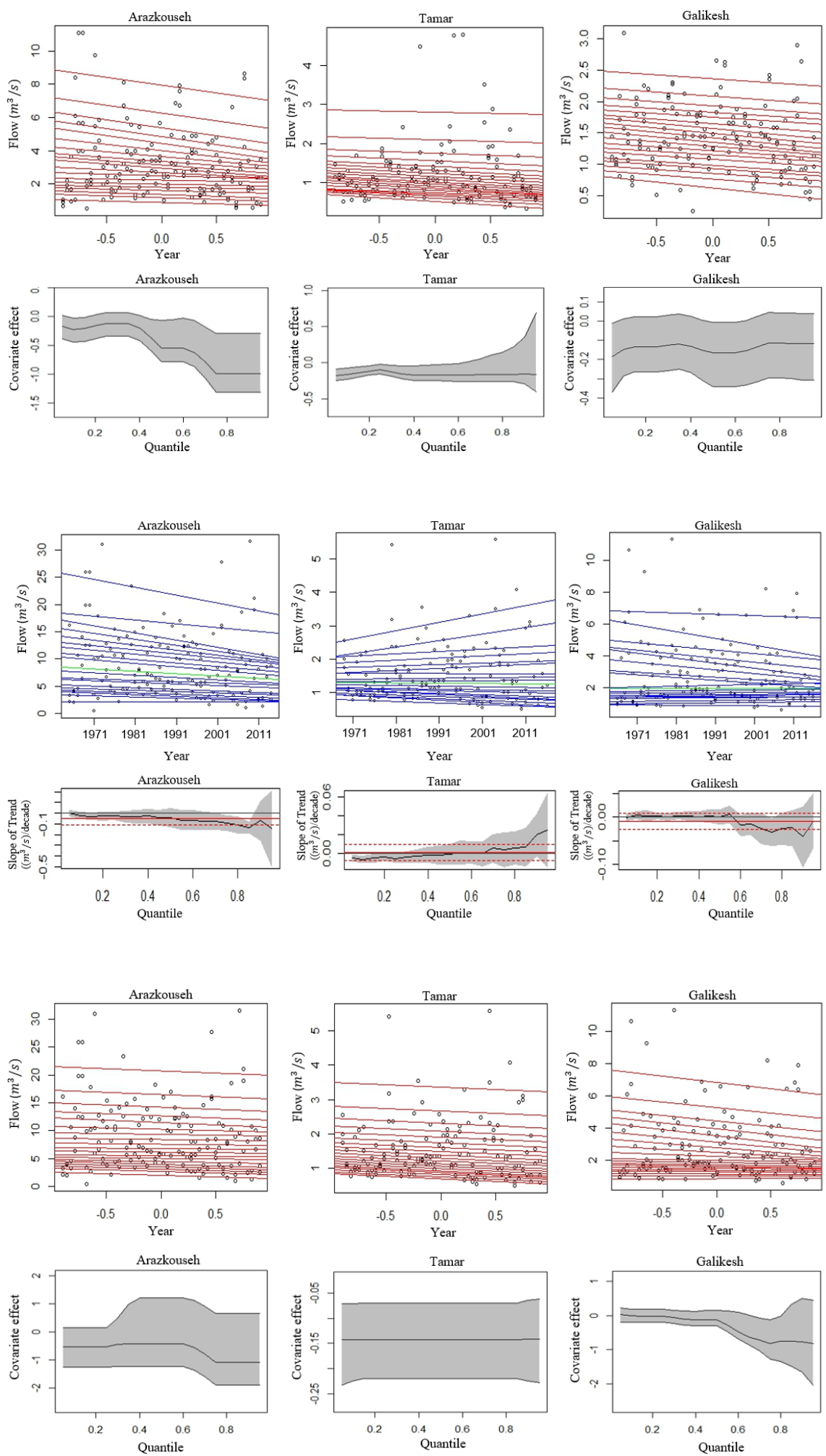